\title{
ARQUITETURA DA PARTICIPAÇÃO E CONTROLES DEMOCRÁTICOS NO BRASIL E NO MÉXICO'
}

ERnesto Isunza Vera

Adrian Gurza LaValle

TRADUÇÃo DE JOSÉ SZWAKO E LILIANA SANJURO

\section{RESUMO}

A multiplicação de experiências participativas visando ampliar o controle social sobre políticas e políticos tornou-se fenômeno relevante no Brasil e mundo afora. Neste artigo é apresentado um quadro analítico útil à comparação da diversidade da inovação democrática enquanto arquitetura da participação orientada para o controle social. Mediante a aplicação desse quadro, examinamos a configuração de duas arquiteturas contrastantes, originárias de dois contextos nacionais distintos: México e Brasil.

PALAVRAS-CHAVE: arquitetura da participação; controles democráticos; accountability; controle social.

\section{ABSTRACT}

The proliferation of experiences of participation that envisage the widening of social control over policies and politicians has become an important feature of Brazilian political landscape, as it has worldwide. This article suggests a useful analytical framework for comparing the diversity of these innovative democratic mechanisms as participatory designs oriented towards social control. With the help of this framework, we examine the configuration of two contrasting designs of different national origins: Mexico and Brazil.

KEYWORDS: Participation design; democratic control; accountability; social control.

[*] Este artigo foi escrito graças à parceria entre o Centro de Estudos da Metrópole (CEM) e o Centro de Investigaciones y Estudios Superiores en Antropología Social (CIESAS). Os autores agradecem o financiamento do CEM para a pesquisa que consubstancia a parceria, bem como à Fapesp e ao CNPq, em cujos programas de financiamento (CEPID e INCT) encontra-se inscrito o CEM.

[1] Pires, Roberto (org.). Efetividade das instituições participativas no Brasil: estratégias de avaliação. Brasília:IPEA, 2011; e Avritzer, Leonardo (org.). A dinâmica da participação local no Brasil. São Paulo: Cortez, 2010.
Na América Latina houve uma multiplicação de experiências participativas orientadas, implícita ou explicitamente, pelas noções de accountability e controle social democrático sobre atores políticos e políticas públicas. Avaliar o alcance e as limitações dessas experiências, bem como identificar os fatores que aumentam ou obstruem sua capacidade, constitui um exercício particularmente fértil para sociedades nas quais foi arriscada a implantação de tais experiências na expectativa de melhorar a qualidade das políticas públicas e de reduzir diversos déficits das instituições políticas que ordenam a vida de tais sociedades. Esse é especialmente o caso do Brasil, onde a institucionalização de experiências participativas colocou o desafio de desenvolver um campo de investigação sobre as chamadas "instituições participativas" e sua efetividade. 
Porém, a diversidade institucional de inovação em termos de controles sociais democráticos e a u sência de ferramentas analíticas que a tornem comparável desafiam as melhores intenções e, não raro, levam a estratégias de análise concentradas em estudos de caso. Examinamos alhures as características comuns da inovação democrática na América Latina e reconstruímos suas conexões com a evolução teórica do debate sobre accountability social, representação e participação². Neste artigo, oferecemos um quadro analítico útil à comparação da diversidade da inovação democrática enquanto arquitetura da participação orientada para o controle social. Mediante a aplicação desse quadro, examinamos a configuração de duas arquiteturas contrastantes, originárias dos contextos mexicano e brasileiro. Primeiro, examinamos a arquitetura de duas experiências de inovação emblemáticas e de nível nacional nos dois países, nomeadamente, o Instituto Federal Eleitoral (IFE) do México e os conselhos gestores de políticas no Brasil. Em seguida, replicamos a operação em duas experiências de controle social democrático de escala municipal e de natureza muito distinta, na medida em que se trata de experiências de controle social especializadas e bem-sucedidas, mas inscritas no seio da sociedade civil. São elas o Grupo Multissetorial HIV-AIDS, no estado de Veracruz (México), e a Rede Nossa São Paulo. Apesar das diferenças de escopo e do caráter civil dos agentes aí envolvidos, a observação dessas duas últimas experiências citadas confirma traços encontrados nas primeiras. A avaliação é um exercício preliminar, mas gera resultados instigantes e anima a construção de teoria e a produção de novos conhecimentos. Em termos teóricos, o exercício aponta para a possibilidade de caracterizar regimes de controle social democrático em escalas municipal, estadual ou nacional - para cuja caracterização é indispensável desenvolver estruturas analíticas capazes de orientar a descrição sintética das arquiteturas de participação. Por sua vez, os resultados são preocupantes com respeito à fragilidade estrutural do sistema de controles sociais democráticos no México, mas, por outro lado, esclarecem algumas das características mais interessantes da experiência brasileira, com as chamadas instituições participativas, e, em ambos os casos, indicam desafios.

\section{ARQUITETURAS dA PARTICIPAÇÃO ORIENTADA PARA O CONTROLE}

Na América Latina, o repertório de inovação institucional no campo do controle social democrático é amplo. Inclui, em contextos específicos, órgãos colegiados para a definição e a fiscalização de políticas, para a elaboração de prioridades nas áreas de planejamento ou de alocação de gastos públicos, comitês participativos em diferentes níveis da administração pública, instituições eleitorais de caráter civil, obser-
[2] Isunza Vera, Ernesto e Gurza Lavalle, Adrian (orgs.). La innovación democrática en América Latina. Tramas y nudos de la representación, la participación y el control social. México: CIESAS-UV, 2010. 
[3] Cf. Isunza Vera, E. e Olvera, A. J. (orgs.). Democratización, rendición de cuentas y sociedad civil: participación ciudadana y control social. México: Ciesas-UV-Miguel Ángel Porrúa, 2006; Grindle, Merilee S. 1999. Audacious Reforms. Institutional Reform and Democracy in Latin America. Baltimore: Johns Hopkins University Press; Hevia de la Jara, Felipe. "Participación ciudadana institucionalizada: análisis de los marcos legales de la participación en América Latina". In: Dagnino, E., Olvera, A. J. e Panfichi, A. (coords.) La disputa por la construcción de la democracia enAmérica Latina. México: FCE-CIESAS-UV, 2006.

[4] Cf. Heller, Patrick. "Moving the State: The Politics of Democratic Decentralization in Kerala, South Africa, and Porto Alegre". Politics and Society 29, 2001; Gaventa, John. "Representation, Community Leadership and Participation: Citizen Involvement in Neighborhood Renewal and Local Governance". Neighborhood Renewal Unit Office of Deputy Prime Minister. Londres, 2004; Santos, Boaventura de Sousa. Democracia e participação: o caso do orçamento participativo de Porto Alegre. Porto Alegre: Afrontamento, 2002.

[5] Gómez-Jáuregui, Jésica. "Participation in Reproductive Health Policies in the Context of Health System Reform in Mexico", IDS Bulletin, vol. 38, n. 6, Brighton, 2008.

[6] Isunza Vera, E. "El reto de la confluencia. Las interfaces socioestatales en el contexto de la transición política mexicana (dos casos para la reflexión)". In: La disputa por la construcción de la democracia en América Latina, 2006. vatórios cidadãos, comissões de vigilância, ouvidorias e supervisões (veedurías) regionais - para citar apenas alguns casos emblemáticos da proliferação de instâncias, geralmente colegiadas, de participação e representação dos cidadãos e da sociedade civil em toda a região3. Essa proliferação não é, aliás, uma excepcionalidade regional. Basta lembrar aqui experiências famosas de outras latitudes como as Emendas Constitucionais 73 e 74 na Índia, a conhecida People's planning campaign do estado de Kerala (Índia), o Local Government Code nas Filipinas ou o New Localism na Inglaterra para perceber quão difundida é a inovação democrática voltada para o exercício de diferentes graus de controle social democrático por cidadãos e organizações civis sobre as instituições políticas e as políticas públicas 4 .

No México e no Brasil, como em todos os países da América Latina, as iniciativas institucionais são variadas. Se observarmos apenas as experiências que obtiveram presença territorial considerável e notoriedade além das fronteiras nacionais, o panorama parece dominado por um conjunto menor de inovações em escala sem precedentes: no Brasil, Conselhos Gestores de Políticas Públicas, Conferências Nacionais de Política, bem como as experiências do Orçamento Participativo, e em menor medida os Planos Plurianuais e os Planos Diretores; já no México, a estrutura federal do IFE, que organiza a participação e o controle cidadãos no sistema eleitoral mexicano, e o sistema de proteção do direito à informação pública governamental (institucionalmente cristalizado no IFAI).

Se nos concentramos, porém, em experiências setorial ou territorialmente mais circunscritas, a diversidade da inovação democrática se manifesta em sua plenitude. Seria o caso, por exemplo, de experiências relativamente bem-sucedidas e com capacidade de incidência sobre as políticas setoriais no México. Nesse conjunto, poderíamos incluir a criação do Grupo Interinstitucional de Salud Reproductiva durante o governo Zedillo, do Consorcio Nacional en Salud y la Mujer com o apoio do secretário de Saúde, Julio Frenk, na administração presidencial de Fox ${ }^{5}$, ou, em âmbito regional do mesmo setor, do Grupo Multissetorial HIV-AIDS no estado de Veracruz ${ }^{6}$. No Brasil, o panorama das instâncias de participação local se assemelha a uma "selva institucional", na qual a multiplicação dos espaços com orientação subsetorial e trans-setorial parece ser a regra. Por exemplo, no município de São Paulo ou em um município vizinho como o de Guarulhos, com uma população quase cinco vezes menor que a do primeiro, desconsiderando-se as instâncias submunicipais de participação - i.e., por distritos administrativos ou por subprefeituras -, existem no mínimo 35 conselhos, câmaras e comissões de âmbito municipal, dentre os quais a maioria esmagadora é de criação voluntária da prefeitura ou não obrigatória por 
lei, como o Conselho Municipal de Atenção à Diversidade Sexual, o Conselho de Proteção e Defesa dos Animais, o Conselho Municipal de Participação da Comunidade Nordestina e o Conselho Municipal de Turismo, entre outros7.

Reconhecendo essa diversidade comum a ambos os casos, parece pertinente perguntar a respeito dos benefícios cognitivos de um exercício de análise comparativa que, forçosamente, levaria a igualar instâncias de índole muito variada. Ora, pensar a participação nos termos de sua arquitetura é, para nós, ser capaz de descrever experiências específicas valendo-se de uma linguagem estrutural que permita não somente reconstruir os significados específicos, quando descrições qualitativas tornam-se necessárias, mas também, e simultaneamente, identificar traços comuns nas configurações arquitetônicas úteis à produção de conhecimento mais abstrato e generalizável. Esse segundo movimento permite construir uma visão de conjunto de uma multiplicidade de instâncias que, de fato, compartilham um senso comum de origem ligado ao contexto pós-Guerra Fria e pós-transições, eque estão dentro de um processo maior de inovação institucional ${ }^{8}$. Além disso, a despeito das razões conjunturais subjacentes à criação das diferentes instâncias de participação e das atribuições particulares a elas conferidas, trata-se, com intensidade e extensão variáveis, de uma tendência de pluralização institucional das democracias ${ }^{9}$, inclusive das democracias do hemisfério Norte ${ }^{10}$.

Assim, de uma perspectiva mais ampla, as arquiteturas dessas inovações podem ser pensadas em seus traços estruturais comuns, bem como em suas eventuais articulações, no sentido da caracterização - e edificação - de regimes de controle democrático. As ideias de sistema político e separação de poderes são, hoje, notadamente insuficientes para dar conta da complexidade dos controles democráticos intraestatais, multiplicados nas últimas décadas. Essa inadequação é certamente ainda maior para a compreensão dos controles democráticos propriamente sociais. Nesses termos, diagnosticar as principais características arquitetônicas dessas inovações institucionais encerra a promessa de aproveitar a riqueza da análise detalhada a respeito de instâncias específicas de participação e representação cidadã e da sociedade civil, sem, contudo, abrir mão de uma visão sintética que permita identificar regimes nacionais e subnacionais de controles democráticos. A distância entre a apreensão qualitativa de uma inovação institucional específica, sua descrição formal ou arquitetônica e a eventual reconstrução de regimes de controle democrático é considerável - nossa aposta é encurtar essa distância tornando esse caminho analiticamente mais transitável.
[7] Tatagiba, Luciana. "Participação e reforma do Estado: sobre a arquitetura da participação em São Paulo". In: O’Donnell, Guillermo, Tulchi, Joseph S. e Varas, Augusto (orgs.). New Voices in the Study of Democracy in Latin America. Washington: Woodrow Wilson International Center for Scholars, 2008, pp. 221-73; Gurza Lavalle, Adrian, Oliveira, Osmany, Serafim, Lizandra e Voigt, Jéssica. “Guarulhos as best case - mapping participatory governance structure and social conflicts". Relatório de pesquisa Chance 2 Sustain Project (manuscrito), 2011.

[8] Cf. Plotke, David. "Representation is Democracy". Constellations 1: 19-34, 1997; Schmitter, C. Philippe. "The future of 'Real-Existing' Democracy". Society and Economy, vol. 33, n. 22, pp. 399-428, ago. 2011; Gurza Lavalle e Isunza. "A trama da crítica democrática: da participação à representação e à accountability". Lua Nova, CEDEC,v. 84, pp. 95-140, 2011.

[9] Gurza Lavalle, Adrian, Houtzager, Peter e Castello, Graziela. "Democracia, pluralização da representação e sociedade civil”. Lua Nova, CEDEC, v. 67, pp. 49-103, 2006.

[10] Cain, Bruce E., Russell, J. Dalton e Scarrow, Susan E. (orgs.). Democracy Transformed?: Expanding Political Opportunities in Advanced Industrial Democracies. Oxford: Oxford University Press, 2003. 
[11] Originário da linguística, o conceito actante foi re-significado por Bruno Latour como parte da sua teoria do ator-rede, que permite contemplar atores humanos e não humanos, bem como discursos. [N. do T.]

[12] García Selgas, Fernando J. "Análisis de sentido de la acción: trasfondo de la intencionalidad". In: Delgado, Juan e Gutiérrez, Juan (orgs.).Métodosy técnicas cualitativas de investigación en ciencias sociales. Madri: Síntesis, 1994.

[13] Long, Norman. Sociología del desarrollo. Una perspectiva centrada en el actor. México: CIESAS-El Colegio de San Luis, 2007.

\section{O fERRAMENTAL ANALÍTICO: PERSPECTIVA RELACIONAL MULTINÍVEL}

Como comparar a diversidade ou como fazer desse caminho algo mais transitável? Não se trata de propor um modelo normativo; nosso ferramental analítico é, antes, útil à descrição e à análise formal das complexas interfaces socioinstitucionais das experiências de controle social democrático. A perspectiva relacional multinível centrada nos dispositivos, por nós apresentada de modo bastante breve, opera em três níveis de abstração unificados pelo privilégio dado, no plano cognitivo, à análise relacional dos diferentes tipos de atores sociais envolvidos nas inovações de controle democrático:i) no nível micro, a atenção sevolta para a dinâmica situacional dos atores concretos em determinada interface de controle social; ii) no nível intermediário (ou meso), importa a interação institucional relevante tal como ordenada nos dispositivos de controle; e iii) no nível macro, são privilegiadas as condições estruturais, isto é, uma visão de sistema da atuação ou das posições reservadas aos respectivos actantes ${ }^{11}$. A descrição formal e integrada do segundo e do terceiro níveis permite identificar arquiteturas institucionais da participação orientada para o controle. A investigação dos efeitos realmente produzidos e das dinâmicas realmente presentes, incluídas no primeiro nível, exige um deslocamento da arquitetura aos conteúdos, quer dizer, do plano da pesquisa empírica estrutural ao da pesquisa empírica qualitativa centrada no exame das interações e das trocas em jogo nas interfaces entre seus diversos atores.

Os atores concretos se relacionam em função de um conjunto de relações diretas transcorridas nas interfaces socioestatais, por meio de arranjos institucionais determinantes dos procedimentos que ordenam tais relações em função dos resultados pretendidos. Além disso, eles se relacionam em função de condições estruturais de atuação definidas institucionalmente que, a princípio, definem as capacidades de ação para possíveis atores — os chamados actantes. Assim, no primeiro nível, mais concreto, por meio da noção de interface, é possível ordenar a descrição e a análise das interações entre os atores, sejam eles sociais ou estatais. $O$ conceito de interface - social, estatal ou socioestatal - remete à ideia de um espaço constituído por sujeitos intencionais ${ }^{12}$, cujas relações — na maior parte das vezes — assimétricas com outros sujeitos estabelecem um espaço de conflito, de negociação e disputa ${ }^{13}$.

Em uma escala de análise maior, os dispositivos (e não os atores) orientados para o controle aparecem no aparato conceitual para pensar a dimensão intrainstitucional relevante na definição das possibilidades das ações sociais. Os dispositivos regulam as faculdades e os recursos institucionais disponíveis aos diferentes atores. Contudo, embora definam as lógicas institucionais de atuação, eles não determinam, nem sequer 
definem por completo, as interações entre os atores específicos. Dito de outra forma, as instituições de controle democrático não mantêm relações in totum com os cidadãos e os atores sociais. Essas relações se dão, antes, através de dispositivos específicos (como, por exemplo, ouvidorias, queixas ou audiências), de modo que eles apresentam lógicas, não apenas distintas, mas também próprias, ainda que pertençam a uma mesma instituição. Assim, para retomar um jargão caro ao institucionalismo, as instituições que importam são os dispositivos. $O$ conceito "dispositivos" nos permite ligar a perspectiva da interface (atores concretos e suas interações) a uma visão de sistema (actantes e suas relações), a fim de avançar duplamente: para além de descrições normativamente carregadas e de descrições reféns de dados pontuais incapazes de iluminar a lógica mais ampla das políticas de controle social democrático presentes em determinado contexto.

É no nível macro, finalmente, que as posições relacionais estruturais dos tipos de actantes são contempladas. Actantes entendidos como posições em uma rede de significado e de capacidades pré-constituídas de ação, que podem corresponder a um ator, a uma instituição, a uma articulação de atores e, mesmo, a dispositivos ${ }^{14}$. Como produto do esforço de decomposição máxima, é possível distinguir quatro tipos de actantes: a sociedade (S), o Estado (E) e a sociedade civil (SC). Dentro do Estado podemos reconhecer o quarto actante: instituições voltadas para o controle de outras instituições estatais - sendo esta uma característica complementar, como nas comissões de fiscalização parlamentar, ou central, como no caso de ombudsman ou tribunais de contas públicas. Vamos chamar instituições como essas de agências de prestação de contas (Arc).

Para o diagnóstico da arquitetura da participação orientada para o controle é necessário definir a lógica institucional da ação, ou seja, a definição institucionalmente dada pelo dispositivo daquilo que é o bem básico de troca, seu sentido (em que direção ou em quais direções se dá tal troca), bem como sua lógica de intercâmbio. Depois de algumas tentativas e ensaios ${ }^{15}$, chegamos à formalização de três grupos de significados nos quais os bens trocados podem ser "informação", "poder" e "bens e serviços". Nos termos das ações entre os atores, esses grupos incluem, respectivamente, "fazer saber", "fazer fazer" e "fazer ter". Desse modo, a descrição das arquiteturas de participação orientada para o controle pode ser analiticamente concebida com referência a uma constelação de dispositivos configurados por múltiplas interfaces de representação, informação, provisão e controle. Por outro lado, vale lembrar que a direção das ações pode, logicamente, se dar de três formas ${ }^{16}$ : provenientes do primeiro sujeito, do segundo sujeito ou em ambas as direções. O Quadro 1 expõe, embora não de maneira exaustiva, essa perspectiva. Nele, utilizamos vetores para representar
[14] Latour, Bruno. Reensamblar lo Social: una introducción a la teoría del actor-red. Buenos Aires: Manantial, 2008.

[15] Cf. Isunza Vera, Ernesto e Hevia de la Jará, Felipe. Relaciones sociedad civil-Estado en México. Un ensayo de interpretación. Xalapa: CIESAS-Universidad Veracruzana, 2006; Isunza Vera, Ernesto. "Para analizar los procesos de democratización: interfaces socioestatales, proyectos políticos y rendición de cuentas". In: Isunza e Olvera, op. cit., 2006; Isunza Vera, Ernesto. "Rendición de cuentas desde una perspectiva comparada en América Latina. El caso de la ciudad de São Paulo". In: Hernández, A. (coord.) Experiencias de Accountability horizontal y social en América Latina: estudios de caso comparados en Brasil, México, Venezuela y Colômbia. Bogotá: Unidandes, 2011.

[16] Na formalização das redes sociais, as matrizes representam quatro possibilidades de conexão: inexistente, com vínculo entrante, com vínculo saliente e com vínculo recíproco (ver Hanneman, Robert A. Introducción a los métodos de análisis de redes sociales, <http://wizard.ucr.edu/ rhannema/ networks/text/textindex.html , acessado em out. 2010). 
[17] Por economia de espaço, excluímos a apresentação e a aplicação da dimensão temporal - controle ex ante, durante e ex post. a direção das relações, a nomenclatura dos tipos básicos de actantes e elementos gráficos para representar os bens básicos ("informação", "poder" e "serviços e bens") das trocas mediante os vetores ${ }^{17}$.

\section{QUADRO 1}

Tipos de lógica de ação e troca

\begin{tabular}{|c|c|c|c|c|}
\hline Gráfico & Bem básico de troca & Gramática relacional & Lógica da ação & Exemplos \\
\hline $\mathrm{S} \rightarrow \mathrm{E}$ & \multirow{3}{*}{ Informação } & Sociedade informa o Estado & \multirow{3}{*}{ Fazer saber } & $\begin{array}{l}\text { Consultas não vinculantes } \\
\text { Caixas de queixas } \\
\text { Pesquisa de opinião de usuários }\end{array}$ \\
\hline$S \leftarrow E$ & & $\begin{array}{l}\text { Sociedade é informada } \\
\text { pelo Estado }\end{array}$ & & $\begin{array}{l}\text { Campanhas midiáticas estatais } \\
\text { Transparência e acesso a informação governamental } \\
\text { Relatórios periódicos }\end{array}$ \\
\hline $\mathrm{S} \leftrightarrow \mathrm{E}$ & & $\begin{array}{l}\text { Sociedade e Estado se } \\
\text { informam mutuamente }\end{array}$ & & $\begin{array}{l}\text { Conselhos consultivos } \\
\text { Mesas de diálogo }\end{array}$ \\
\hline$S \Rightarrow E$ & \multirow{3}{*}{ Poder } & Sociedade 'mandata' o Estado & \multirow{3}{*}{ Fazer fazer } & $\begin{array}{l}\text { Eleições } \\
\text { Referendo, plebiscito, mandato revogatório }\end{array}$ \\
\hline $\mathrm{S} \bullet \mathrm{E}$ & & $\begin{array}{l}\text { Sociedade é 'mandada' } \\
\text { pelo Estado }\end{array}$ & & Políticas terceirizadas \\
\hline $\mathrm{S} \Leftrightarrow \mathrm{E}$ & & $\begin{array}{l}\text { Sociedade e Estado se } \\
\text { 'mandatam' mutuamente }\end{array}$ & & $\begin{array}{l}\text { Conselhos deliberativos } \\
\text { Orçamentos participativos }\end{array}$ \\
\hline$S \rightarrow E$ & \multirow{3}{*}{ Bens e serviços } & Sociedade provê o Estado & \multirow{3}{*}{ Fazer ter } & Impostos \\
\hline$S \leftarrow E$ & & $\begin{array}{l}\text { Sociedade é provida } \\
\text { pelo Estado }\end{array}$ & & $\begin{array}{l}\text { Transferências } \\
\text { Subsídios }\end{array}$ \\
\hline $\mathrm{S} \leftrightarrow \mathrm{E}$ & & $\begin{array}{l}\text { Sociedade e Estado se } \\
\text { proveem mutuamente }\end{array}$ & & $\begin{array}{l}\text { Obras com trabalho dos beneficiários } \\
\text { Projetos de coinvestimento }\end{array}$ \\
\hline
\end{tabular}

\section{A ARQUITETURA dA PARTICIPAÇÃO COMO SISTEMA DE CONTROLE NO MÉXICO E NO BRASIL}

Da perspectiva relacional multinível, um breve olhar sobre uma das inovações de controle democrático selecionadas, e mais especificamente, sobre seus dispositivos de controle em perspectiva diacrônica, revela uma arquitetura com possibilidades de controle muito específicas relacionadas à sua concepção, alcances e formas de participação e representação social.

Vejamos, primeiro, o Instituto Federal Eleitoral (IFE), a autoridade que organiza as eleições federais (presidente, senadores e deputados) no México (Quadro 2). O órgão máximo do IFE é o Conselho Ge$\mathrm{ral}$ (CG), um grupo de nove pessoas (conselheiros) eleitas, por uma maioria de dois terços dos deputados federais, para exercer o controle da instituição. As tarefas de controle são de responsabilidade do CG, 
com 192 cidadãos nos 32 órgãos estaduais descentralizados (seis pessoas em cada conselho local) e 1800 pessoas em nível distrital (seis em cada conselho distrital nos trezentos distritos eleitorais). Eles têm poderes formais para exercer o máximo controle dentro do IFE: apenas os conselheiros, chamados de "cidadãos", têm direito a voto, junto com os presidentes de cada conselho local e distrital; estes últimos, ao mesmo tempo, são os chefes da estrutura burocrática do seu âmbito (institutos eleitorais estatais). Sobre isso, vale notar dois pontos: a relação entre conselheiros e cidadania é um fato significativo apenas no momento das eleições, quando milhares de cidadãos participam como membros das mesas receptoras de votos. Paralelamente à ação da cidadania e dos conselheiros cidadãos, operam agências de prestação de contas específicas, quais sejam, o Tribunal Eleitoral do Poder Judicial da Federação e do Procurador Especial de Atenção a Crimes Eleitorais, órgão especial do Ministerio Público Federal ${ }^{18}$.

A relação $\mathrm{S}=\mathrm{SC}$ (cidadania representada pelos conselheiros eleitorais cidadãos) não é um caso de representação por autorização, mas sim de representação presuntiva em uma instituição do sistema político'19. Quer dizer, uma representação mediada pelos deputados que indicam os conselheiros cidadãos, muitas vezes, "notáveis" da sociedade civil. O Conselho Federal Eleitoral (GC) - tal como os conselhos eleitorais estatais - é um exemplo de dispositivo de controle transversal, no qual representantes civis (SC) atuam dentro do Estado e mantêm uma relação de cogestão com funcionários públicos do IFE (E), para a realização de eleições e a mediação das disputas partidárias.

\begin{abstract}
[18] O Tribunal qualifica as eleições presidenciais em última instância. Cumpre mencionar que o Ministério Público no México (a Procuraduría de Justicia) não é autônomo do Executivo, como ocorre no Brasil. Cf. Isunza Vera, Ernesto. "Árbitros ciudadanos de las disputas partidarias. Una mirada sobre los consejos electorales federales en la contienda de 2000 en México". In: Isunza e Olvera, op. cit., 2006; Aziz Nassif, Alberto e Isunza Vera, Ernesto. "La crisis del modelo electoral mexicano: financiamiento, medios, instituciones y política social". Foro Internacional 4, 2007, pp. 740-84.
\end{abstract}

[19] Cf. Gurza Lavalle, Adrian, Houtzager, Peter e Castello, Graziela. "Representação política e organizações civis: novas instâncias de mediação e os desafios da legitimidade". Revista Brasileira de Ciências Sociais, v. 21, n. 6o, 2006, pp. 43-66; Gurza Lavalle, Adrian e Castello, Graziela. "Sociedade civil, representação e a dupla face da accountability: Cidade do México e São Paulo". Caderno CRH, UFBA, v. 21, 2008, pp. 67-86.

\section{QUADRO 2}

Análise estrutural dos Conselhos Eleitorais do IFE

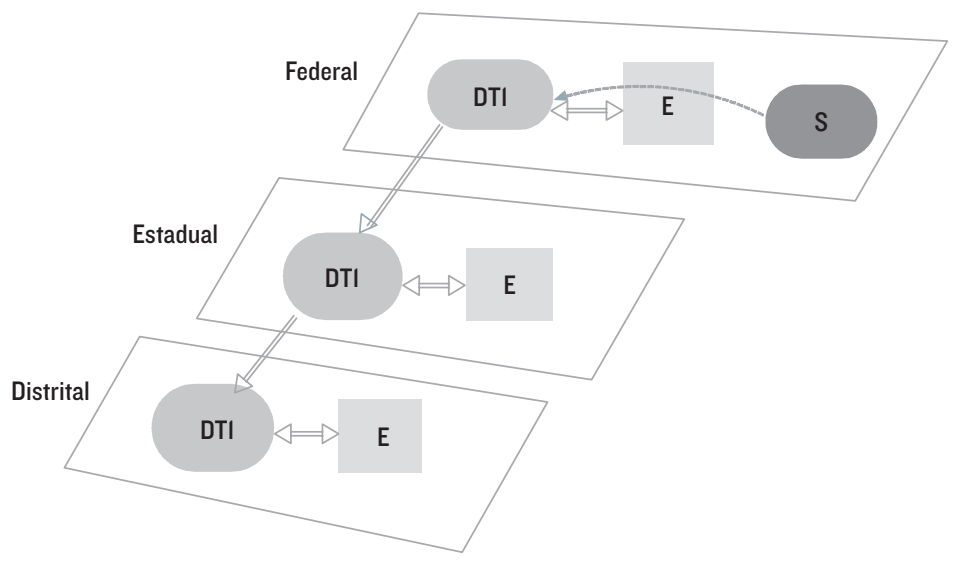


[20] Tatagiba, op. cit.; Teixeira, Ana Claudia e Tatagiba, Luciana. “Democracia participativa en la ciudad de São Paulo: continuidades y rupturas". In: Isunza e Gurza Lavalle, op. cit., 2010.

[21] Silva, Marcelo K., Cortes, Soraya M.V., Réos, Janete C.e Barcelos, Márcio. "Cuando nuevos personajes dominan el escenario: recursos organizativos y relaciones de poder en el Consejo Nacional de Salud de Brasil". In: Isunza e Gurza Lavalle, op. cit., 2010.
Os conselhos eleitorais cidadãos do IFE, como dispositivo de controle transversal, estão representados como "dispositivo transversal l " (DT1), os funcionários públicos como (E) e a cidadania em geral como (S). A arquitetura mostra que a cidadania é representada de maneira presuntiva, por meio da indicação feita pelos deputados federais quanto à composição do Conselho Geral do IFE. Como se vê, a estrutura do IFE está conformada em três âmbitos (distrital, estadual e federal), e em um sentido de legitimidade/ representação "de cima para baixo".

O modelo da arquitetura de conselhos gestores de política pública no Brasil revela contrastes. Nesse caso, são basicamente as organizações da sociedadecivile,em menor medida, subpúblicos determinados quevotam ou fazem acordos para a integração dos representantes ou conselheiros da sociedade civil. Os conselhos e conselheiros, no plano arquitetônico, participam nas três etapas da política, incluindo o planejamento, a implementação e a avaliação ex post da política, embora haja variações significativas entre os diferentes conselhos setoriais, de modo que os conselhos de saúde são aqueles mais plenamente desenvolvidos ou exemplares desse modelo. Deve-se enfatizar que existem, nesse modelo, instâncias de adensamento de consensos e de definição de prioridades entre atores da sociedade civil, pelo que os conselhos se encontram conectados a subpúblicos da sociedade civil, mas também às comunidades das políticas setoriais, contemplando burocracias públicas e privadas, poder executivo e organizações econômicas. Os chamados fóruns temáticos e as conferências espelham esse tipo de instância de adensamento, as primeiras, em geral, constituídas por atores da sociedade civil, e as segundas por atores das comunidades de políticas. Em ambos os casos se dão acordos que, seja em nível municipal, estadual ou federal, orientam as decisões dos conselheiros civis, ao modo deum "mandato facultativo". Para além das limitações ecríticas das formas efetivas de concretização de tal modelo ${ }^{20}$, na realidade, a arquitetura dos conselhos gestores remete à cogestão — rara em outras latitudes com as mesmas extensão e diversidade temática encontradas no Brasil21.

O Quadro 3 mostra a arquitetura desse dispositivo de controle transversal societal. Nele, conselhos gestores de políticas públicas são representados como "dispositivo transversal l" (DT1), mostrando suas relações com os funcionários públicos (E) que implementam a política em questão (saúde, educação etc.) e fóruns temáticos e conferências (DS1, DS2), que desempenham o papel de mediadores para organizar o debate público sobre a política no sentido de adensar e viabilizar consensos dentro dos atores tematicamente interessados da sociedade civil (fóruns) e dentro das comunidades de políticas (conferências).

Outro elemento a ser destacado nessa arquitetura orientada para o controle das políticas públicas é a presença de fundos para o financiamento da política setorial (DT2) que operam sob supervisão e com representação dos conselhos setoriais específicos. A estrutura conse- 


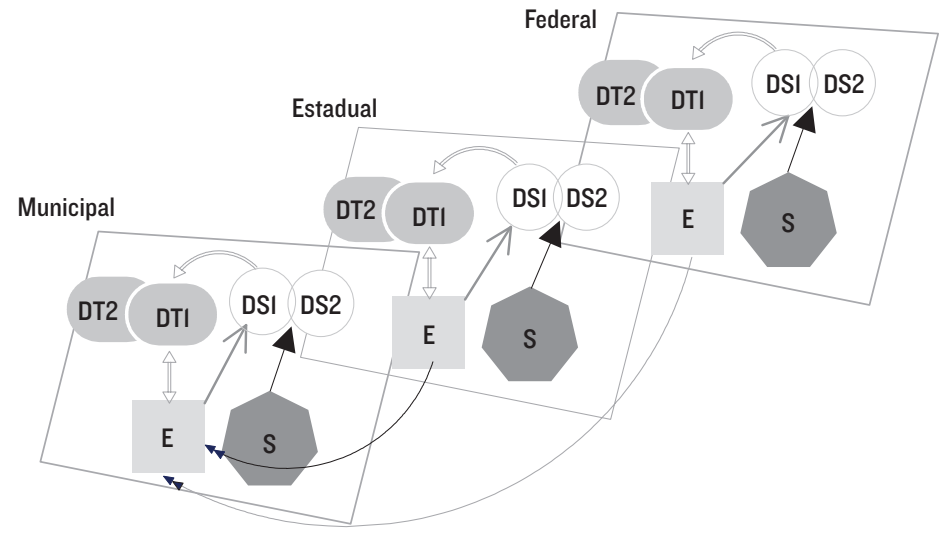
DSI Foros temáticos
DTI Conselhos gestores
DS2 Conferências
DT2 Fundos Setoriais

lhista opera com lógica federativa, replicando sua estrutura em cada nível da federação, incluindo-se aí os dispositivos societais. A adoção dos conselhos no nível municipal, em alguns casos setoriais como o da saúde, foi estimulada por meio de transferências condicionadas de recursos federais. Ainda que as transferências obedeçam a uma lógica de coordenação que vai das definições federais para a implementação municipal — "de cima para baixo" — , a configuração da legitimação/ representação dos conselheiros civis opera no interior de cada nível federativo e, eventualmente, "de baixo para cima".

Os dois casos examinados são emblemáticos das inovações democráticas em seus respectivos contextos, e em ambos a relação entre atores estatais e sociais é parte importante do desenho do sistema de controle. No primeiro caso, o tipo de representação é presuntivo, mas ligado a um evento originário de legitimidade: a autorização indireta dos conselheiros do Conselho Geral do IFE, com indicação do Congresso. Assim, os partidos escolhem seus controladores. No segundo, os representantes contam com a autorização das organizações civis e, às vezes, de subpúblicos, e incorporam presuntivamente a representação de toda a sociedade ou de segmentos dela diante dos funcionários públicos ${ }^{22}$. O controle dos controladores é, em certa medida, exercido tanto pela indicação dos conselheiros através de acordo (e/ ou porvoto) entre as organizações civis quanto por efeitos de controle, diretos e indiretos, de fóruns e conferências, bem como pelo efeito de "mandato facultativo"

[22] Gurza Lavalle, A., Houtzager P. e Castello, G. "Democracia, pluralização da representação e sociedade civil", op. cit. das instâncias de adensamento de consensos. 
[23] Esta seção está baseada em Isunza Vera, Ernesto. "El reto de la confluencia. Las interfaces socioestatales en el contexto de la transición política mexicana (dos casos para la reflexión)", e sua atualização em Isunza Vera, Ernesto. "Participación ciudadana como control en la escala local de la construcción democrática: herramientas conceptuales y prácticas comparadas México-Brasil".Apresentado no colóquio "La reconnaissance de l'égalité et de la différence: Regards transnationaux sur la démocratisation dans les Amériques". Centre d'études interaméricaines, Institut québécois des hautes études internationales, Universidad Laval, Quebec, Canadá,27e28 de novembrode 2009 .

\section{PARA A IDENTIFICAÇÃO DE TRAÇOS ESTÁVEIS NAS ARQUITETURAS}

Podemos corroborar alguns dos indícios produzidos pela análise relacional dos dispositivos presentes em duas das mais conhecidas experiências de inovação democrática, no México e no Brasil, mediante o exame de duas inovações de controle de menor envergadura - a começar pela sua escala de caráter municipal - e de natureza muito diferente pelo fato de encontrarem-se inscritas dentro da sociedade civil como iniciativas especializadas e exitosas de controle social.

A segunda instância de comparação originária do México é a experiência do Grupo Multissetorial HIV-AIDS de Veracruz (GM, Quadro 4) ${ }^{23}$. Trata-se de um dispositivo de controle de políticas públicas que, poder-se-ia dizer, encontra-se do lado oposto ao IFE em termos de quantidade de recursos financeiros, institucionais e normativos para exercer sua função. Ainda assim, ele tem conseguido incidir na implementação da política pública de luta contra a epidemia do vírus da imunodeficiência humana e a favor das pessoas que vivem com HIV-AIDS. O GM mostra que para exercer controle com algum grau efetivo de institucionalização sobre programas ou políticas públicas nem sempreé necessário obter o reconhecimento constitucional nem contar com recursos financeiros milionários como o IFE. Fundado em abril de 2002, o grupo é formado por indivíduos e organizações provenientes de diversas experiências, desde a luta pelos direitos humanos, passando pela academia e pelo setor de saúde, chegando ao trabalho sexual e à luta contra a discriminação.

\section{QUADRO 4}

Análise Estrutural do Grupo Multisetorial HIV-AIDS

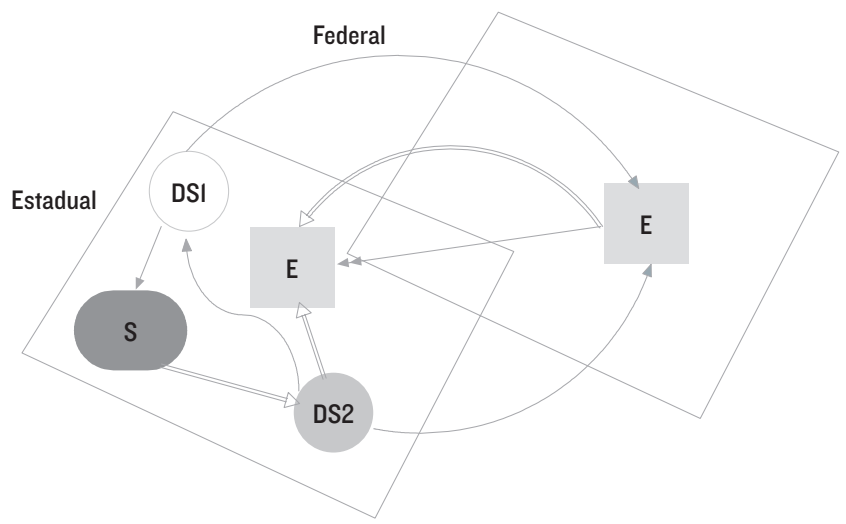

DSI

Meios de informação 
A partir de um acordo com o responsável estatal do setor de saúde em Veracruz, essa rede, não formalizada sob nenhuma figura legal, leva a cabo o monitoramento de clínicas e hospitais, especialmente no que se refere ao programa - que é parte da política nacional - de luta contra a epidemia de HIV-AIDS. Com reuniões de seguimento bimestrais com o secretário de Saúde, ou com maior frequência se algum problema o requer, o GM (DS2) exerce formas de controle baseadas no custo de reputação que eventualmente levaria ao descrédito de funcionários públicos. Utiliza, quando necessário, a publicação de informes e denúncias nos meios de informação de massa (DS1), bem como tem desempenhado trabalho específico para modificar a base normativa de sua atividade. Especificamente, o GM decidiu utilizar a ferramenta da iniciativa popular para criar uma lei estatal contra o HIV-AIDS com o objetivo de situar o tema na agenda regional, mas também para aumentar sua capacidade de interlocução e controle com relação aos funcionários públicos encarregados da área de seu interesse. Com o apoio da Universidade Autônoma de Veracruz, foi possível reunir as 30 mil assinaturas necessárias para que o projeto de lei fosse discutido pela legislatura estatal. Graças a essa mobilização, à qualidade técnica do texto proposto e à conjuntura política adequada, o GM conseguiu que a iniciativa fosse aprovada por unanimidade nos últimos dias de 2008. Um elemento interessante para analisar o papel do GM como dispositivo de controle social é, conforme pode ser observado no Quadro 4, a relação que este guarda com um agente estatal do âmbito federal. Nesse caso, a comunicação favorável do GM com o órgão federal encarregado da política nacional de luta contra o HIV-AIDS favorece o exercício de controle, já que este órgão não apenas transfere recursos ao setor de saúde local e regional, mas também possui faculdades normativas sobre toda a política pública voltada para a epidemia.

No caso do Brasil, a segunda instância de comparação de controle exercido mediante iniciativa da sociedade civil é originária da cidade de São Paulo: trata-se da rede Nossa São Paulo (RNSP) 24. A rede inspirou-se em outras práticas da América Latina como Bogotá Cómo Vamos. Contudo, sua incidência nas políticas da cidade não é nutrida somente por sua capacidade técnica e clareza de agenda, mas, em boa medida, por sua conformação plural e capacidade de convocação e interlocução pública. A RNSP está conformada por agentes que contribuem para sua articulação com dispositivos horizontais e internos de controle do Estado, mas também com dispositivos transversais que são próprios da experiência brasileira, como os fóruns e os conselhos gestores de política pública (ver Quadro 5).
[24] Este trecho retoma de modo sucinto Isunza Vera, Ernesto. "Rendición de cuentas desde una perspectiva comparada en América Latina. El caso de la ciudad de São Paulo". 

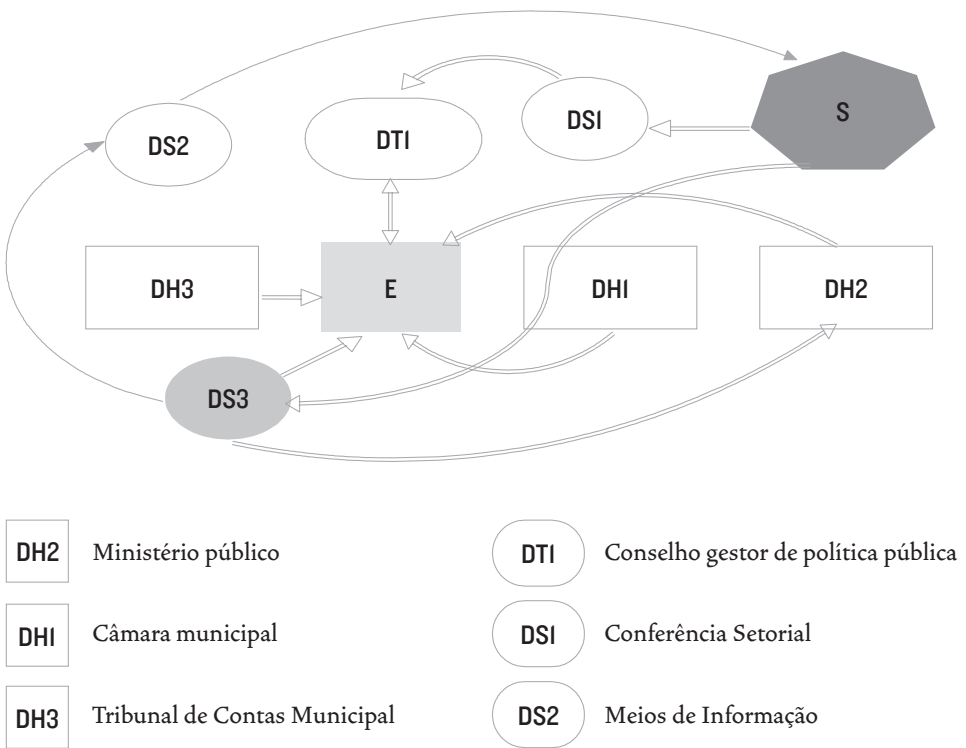

DS3 Rede Nossa São Paulo

A RNSP foi fundada em maio de 2007 e em menos de dois anos contava com um número de filiados superior a quinhentas organizações autodenominadas "de base, empresariais e sociais". Sua organização baseia-se em uma assembleia composta de tais organizações que se articulam em grupos de trabalho. Os recursos financeiros da RNSP (DS3) canalizam-se mediante uma fundação e o trabalho de articulação, e o seguimento dos acordos é realizado por uma secretaria executiva. A metodologia de trabalho consiste em elaborar indicadores e metas, realizar o monitoramento de gestão dos poderes Executivo e Legislativo municipais, assim como na análise e divulgação do orçamento e na permanente consulta da opinião pública, através de surveys, de informações das organizações que a conformam e da comunicação eletrônica com o conjunto da cidadania paulistana mediante seu acesso aos grandes meios de comunicação (DS2). A RNSP mantém o chamado Observatório cidadão: um acompanhamento público dos indicadores de processo e de resultado da gestão do poder público municipal e das condições de vida de seus habitantes. A rede conseguiu articular suas atividades de monitoramento por área e território (as 31 submunicipalidades e os 96 distritos) com a agenda pública da gestão municipal. Também conseguiu negociar a iniciativa pela qual os governantes (desde 2009 ) devem elaborar seu plano de trabalho a partir de suas promessas de campanha, traduzir o plano em indicadores e prestar contas semestrais de seu desempenho com a perspectiva de tais indicadores. 
Um ponto central para compreender o êxito da experiência da RNSP (DS3) é sua relação com os mundos dos atores estatais dedicados ao controle do próprio Estado, das organizações civis e dos movimentos sociais com agenda urbana. A RNSP articula-se com o Ministério Público (DHI) e com o Tribunal de Contas (DH3), bem como mantém conexão permanente com a Câmara de Vereadores (DH2). Ademais, a RNSP estabelece relações não apenas com organizações civis e movimentos como membros da rede, mas com representantes em instâncias nas quais desempenham o papel de agentes de controle social: conselhos (DT1) e conferências (DS1). Como pode ser observado no Quadro 5, tal arquitetura de dispositivos de controle é muito diversa e, de fato, possibilita sinergias entre dispositivos de controle democrático transversais, horizontais, sociais e internos; sinergias raras em outros contextos como o mexicano.

\section{REGIMES DE CONTROLES DEMOCRÁTICOS}

\section{NO MÉXICO E NO BRASIL: ALGUMAS CARACTERÍSTICAS}

A multiplicação de inovações institucionais orientadas ao controle democrático de burocracias, políticos e políticas públicas nos dois hemisférios é parte do espírito do tempo, caminhando lado a lado com a pluralização institucional da democracia e com a crescente percepção de que as eleições e seu mecanismo básico, o voto, embora fundamentais, são um instrumento limitado para controlar os representantes e praticamente nulo para estimular respostas das burocracias aos anseios dos cidadãos 25 . As eleições, devido a seu caráter plebiscitário, não permitem discriminar entre o certo e o errado com relação à atuação dos governos, bem como seu duplo significado, como eleição de futuro entre várias ofertas e/ ou como julgamento crítico das ações do governo em questão, obscurece a mensagem do voto e, com isso, suas possibilidades de induzir o comportamento dos representantes (re)eleitos.

Apesar das reticências dos representantes diante das diversas tentativas de promover maior accountability, para além dos mecanismos de prestação de contas vertical tradicionais, os controles internos, as agências de prestação de contas e as instituições híbridas de controle democrático social se multiplicaram. Tal multiplicação conta com instituições estatais autônomas, como o Ministério Público e os Tribunais de Contas brasileiros, o Instituto Federal de Acesso à Informação e a Comissão Nacional de Direitos Humanos mexicanas, ou os ombudsman e as veedurías de outros países; conta também com diversas formas de controle "externo" e "interno", como as ouvidorias, as controladorias e as auditorias; e, conforme
[25] Przeworski, Adam, Stokes, Susan C. e Manin, Bernard. "Elections and representation". In: Democracy, Accountability and Representation. Cambridge: Cambridge University Press, 1999, pp. 29-54. 
[26] Essas características também foram constatadas comparando tanto a construção política das sociedades civis quanto o modus operandi da sociedade civil na Cidade do México e em São Paulo (ver Gurza Lavalle, Adrian e Bueno, Natália. "Waves of Change within Civil Society in Latin America: Mexico City and São Paulo". Politics \& Society, v. 39, 2011, pp. 415-50; Gurza Lavalle, Adrian, Houtzager, Peter e Castello, Graziela. "La construcción política de las sociedades civiles". In: Gurza Lavalle, Adrian (org.). El horizonte de la politica Brasil y la agenda contemporánea de investigación en el debate internacional. México: CIESAS, 2011. mencionado, com dispositivos mistos como o IFE ou os conselhos gestores de políticas. Além disso, existem iniciativas da sociedade civil não institucionalizadas no Estado que "disparam" os mecanismos de controle externo e horizontal dentro do Estado.

Sem dúvida, diversas inovações específicas merecem e vêm recebendo atenção. Contudo, o processo em curso delineado pela proliferação de tais inovações sugere uma pluralização institucional da qual estão emergindo democracias que não mais respondem às descrições animadas pela doutrina clássica da separação de poderes, nem por conceitos precisos da ciência política do século XX como o de sistema político. A teoria política deste século corresponderá ao desafio de gerar quadros conceituais capazes de oferecer uma visão de conjunto das instituições políticas das democracias.

A perspectiva relacional multinível aqui esboçada e aplicada oferece um instrumental analítico descritivo para a comparação estrutural ou formal de instituições de controle democrático, assumindo o pressuposto de que a acumulação de exercícios comparativos sistemáticos permitirá avançar na caracterização de regimes de controles sociais democráticos. É certo que a comparação metódica não dispensa o desenvolvimento teórico dos critérios conceituais para a especificação de tais regimes, e, nesse sentido, estas páginas contêm não uma teoria, mas uma intenção teórica (perspectiva) munida de distinções conceituais positivas sistemáticas (ferramental) que julgamos úteis.

A comparação entre arquiteturas da participação orientadas ao controle de atores estatais e a definição de políticas públicas revelou traços interessantes que parecem iluminar algumas das características dos regimes de controle democrático no México e no Brasil. O fato de que partidos designem os conselheiros cidadãos de uma instituição (IFE), originalmente pensada como estritamente apartidária e inteiramente civil, mostra o peso dos partidos no domínio dos circuitos não tradicionais de controle democrático no México. Por sua vez, a importância da comunicação fluida entre o GM e o órgão federal responsável pela política de combate ao HIV-AIDS sugere não apenas a persistência do centralismo no federalismo mexicano - neste caso com consequências positivas diante da política local conservadora -, mas também a escassez de apoios locais na institucionalidade pública estatal e municipal. A escassez parece apresentar sua contrapartida na rarefação da sociedade civil local, a julgar pelo tamanho da articulação civil que mantém o GM. Centralismo político, partidocracia e rarefação da sociedade civil na configuração das inovações de controle parecem prefigurar um regime limitado de controles democráticos sociais, vulnerável às mudanças do governo central, às conveniências partidárias e com baixa resiliência quanto às iniciativas não institucionalizadas no Estado ${ }^{26}$. 
Por sua vez, as experiências brasileiras analisadas colocam resultados e desafios opostos. Os conselhos são um caso exemplar da federalização/ municipalização das políticas públicas no Brasil, mas sem dúvida não são únicos em matéria de controle democrático social: as conferências também seguem a estrutura federativa, e os planos plurianuais e os planos diretores são obrigatórios para todos os municípios. A federalização dos controles democráticos sociais chama a atenção porque inevitavelmente pressupõe que a política de controle e da participação tornou-se parte da agenda do Estado. Vale notar também não apenas a presença de vários dispositivos sociais e transversais simultaneamente articulados entre si, e conectados com a sociedade civil e com o Estado, como demonstrado pela conexão entre conselhos gestores de políticas, por um lado, e fundos setoriais, fóruns da sociedade civil e conferências convocadas pelo Estado, por outro, mas o fato de que esses dispositivos se articulam em torno de uma instância - os conselhos - que conta, no plano municipal, com formas de acordo e, por vezes, de autorização próprias e reguladas para a seleção dos representantes da sociedade civil entre organizações civis do mesmo campo temático e entre subpúblicos. A lógica federativa dos conselhos corre nos dois sentidos, de cima para baixo evice-versa, isto é, do plano municipal para o federal, claramente uma lógica distinta das indicações dos consel heiros do IFE mexicano. Por sua vez, a experiência da RNSP mostra um dos traços mais interessantes da inovação democrática no Brasil, a saber: o desenvolvimento de agentes institucionais dentro do Estado com agendas de forte controle horizontal como o Ministério Público e o Tribunal de Contas na experiência analisada - mas também a Polícia Federal ou o Conselho Nacional de Justiça, entre outros exemplos possíveis. As relações com esses agentes institucionais encontram-se entre os recursos mais eficientes das estratégias de controle social de iniciativas civis como a RNSP. Essa iniciativa mostra uma densidade associativa da sociedade civil — associada a, mas não derivável automaticamente do tamanho da cidade - que torna as iniciativas das redes de organizações civis menos vulneráveis aos humores da política eleitoral.

Em suma, no Brasil, a federalização de parte central das inovações de controle democrático social, a institucionalização estatal ou incorporação da questão dos controles democráticos sociais na agenda do Estado, a presença de agentes institucionais do Estado com agendas fortes de controle horizontal, a densidade organizacional da sociedade civil e os efeitos multiplicadores da articulação entre as agendas desses agentes e da sociedade civil prefiguram um regime de controles democráticos sociais amplo, policêntrico e capilar, com potenciais aliados estratégicos de controle horizontal dentro do Estado. Aqui, o desafio não é claramente o de crescimento, senão o de evitar o risco de hipertrofia por conta dos efeitos multiplicadores dos fatores anotados. 
Recebido para publicação em 29 de agosto de 2011.

\section{NOVOS ESTUDOS}

CEBRAP

92, março 2012

pp. 105-121
Há claros indícios de que a definição de um sistema unificado de controles democráticos sociais está na agenda do governo, mas trata-se de uma questão delicada e de futuro incerto.

Avançar na caracterização das arquiteturas da participação orientada ao controle e na compreensão das implicações de seus traços para a configuração de regimes de controles democráticos sociais encerra não somente a possibilidade de compreender e eventualmente explicar esses regimes, mas também, como desde sempre na análise institucional a partir dos federalistas, a promessa de desenhar arquiteturas virtuosas para realidades prosaicas.

ERNESTO ISUNZA VERA é pesquisador do Centro de Investigaciones y Estudios Superiores en Antropología Social (México).

AdRIAN GURZA LAVALle é professor do departamento de Ciência Política da FFLCH-USP, pesquisador do Cebrap e do Centro de Estudos da Metrópole. 